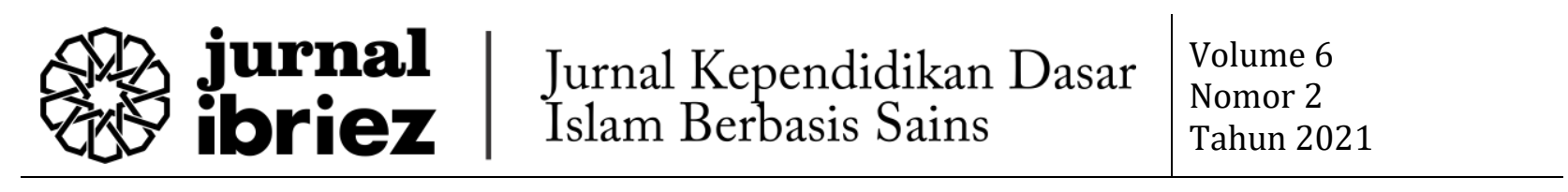

\title{
PENGEMBANGAN VIDEO PEMBELAJARAN STOP MOTION DENGAN APLIKASI WONDERSHARE FILMORA PADA MATA PELAJARAN MATEMATIKA DI SEKOLAH DASAR
}

\author{
Putri Nur Rohmah', Sholeh Hidayat ${ }^{2}$, Aan Subhan Pamungkas ${ }^{3}$, dan Hestu Wilujeng4 \\ 1,2,3,4Universitas Sultan Ageng Tirtayasa \\ Surel: rohmahputrinur@gmail.com
}

\begin{abstract}
Abstrak
Penelitian ini memiliki tujuan supaya media pembelajaran dalam mengembangkan video stop motion pada mata pelajaran matematika sekolah dasar. Adapun dalam materi dituangkan pada video stop motion ini yakni menghitung hasil perkalian. Subjek dalam penelitian yakni peserta didik kelas III SDN Gorda 1 yang berjumlah 21 siswa. Penggunaan metode pada penelitian ini yakni R\&D (Research and Development) melalui model ADDIE (Analysis, Design, Development, Implementation, Evaluate). Data yang dikumpulkan pada penelitian pengembangan yakni melalui cara tanya jawab pada wawancara serta kuesioner (angket). Hasil penelitian menunjukkan bahwa video pembelajaran stop motion memiliki kelayakan dalam penggunaannya sebagai media belajar. Hal tersebut dilihat melalui hasilnya penilaian dilaksanakan dengan validator ahli media dan materi. Hasil dari validasi kepada ahli media yakni senilai 92.1\% kriteria sangat layak, sedangkan validasi kepada ahli materi yaitu 85,3\% kriteria sangat layak. Selain itu, hasil angket respon siswa sebesar 97,6\% kriteria sangat baik, dengan begitu menyimpulkan bahwa video pembelajaran stop motion ini dapat diberikan pemahamannya untuk kelas III SDN Gorda 1 terhadap pembelajaran matematika materi perkalian.
\end{abstract}

Kata Kunci: pengembangan, media pembelajaran, stop motion

\begin{abstract}
This study aims to develop learning media in the form of stop motion videos in elementary school mathematics subjects. The material contained in this stop motion video is calculating the multiplication results. The subjects in this study were students of class III SDN Gorda 1, totaling 21 students. This study uses the R\&D (Research and Development) method with the ADDIE model (Analysis, Design, Development, Implementation, Evaluate). Data collection in this development research is by means of interviews and questionnaires (questionnaire). The results showed that the stop motion learning video was feasible to be used as a learning medium. this can be seen from the results of the assessment conducted by the media and material expert validators. The results of the validation to media experts are $92.1 \%$ with a very decent category, while the validation to material experts is $85,3 \%$ with a very decent category. In addition, the results of the student response questionnaire were $97.6 \%$ with a very good category, so it can be concluded that this stop motion learning video provides an understanding to third grade students of SDN Gorda 1 on multiplication material learning mathematics.
\end{abstract}


Keywords: development, learning media, stop motion

\section{A. PENDAHULUAN}

Pada prinsipnya, pendidikan tidak bisa terpisahkan dari kegiatan belajar. Oleh sebabnya melalui belajar, pengetahuan dapat diperoleh bagi seseorang yang tentunya akan memberikan sebuah perubahan yang lebih baik. Dalam kegiatan pembelajaran terdapat dua proses yaitu belajar dan mendengarkan, keduanya tersebut merupakan kegiatan yang tidak dapat dipisahkan. Proses pembelajaran dilakukan oleh peserta didik bersama pendidik, dengan pendidik memberikan pengetahuan kepada peserta didik dan mengembangkannya lebih lanjut.

Maka dari itu, menurut Permendikbud No. 22 Tahun 2016 terkait Standar Proses Pendidikan Dasar dan Menengah ${ }^{1}$ bahwa tolak ukur terkait aktifitas belajar dalam melaksanakannya pada satuan pendidikan dasar serta satuan pendidikan dasar menengah agar kemampuan dalam kelulusan dapat tercapai. Dengan demikian, pelaksanaan pembelajaaran harus diselenggarakan dengan cara interaktif, menyenangkan serta dapat memotivasi peserta didik sehingga berguna untuk mengembangkan kualitas yang baik bagi peserta didik melalui segi kognitif (pengetahuan), afektif (sikap)atau psikomotorik (keterampilan).

Kenyataannya, proses pembelajaran pada saat ini dilaksanakan secara konvensional, sebagaimana menurut Wulansari ${ }^{2}$ yakni banyaknya guru yang masih menyampaikan materi hanya dengan metode ceramah yang digunakan serta papan tulis sebagai media pembelajarannya,adapun media pembelajaran yang digunakan selama ini seperti buku lembar kerja pesertadidik atau buku tematik, media gambar ataupun media konvensional yang lainnya.

Apabila diaplikasikan secara menyeluruh pada saat pembelajaran dapat memberikan kesan tidak inovatif dari seorang guru tersebut yang membuat peserta didik tidak aktif di kelas karena bisa dikatakan hanya guru yang fokus mengajar, guru hanya menyetting siswa menjadi pendengar yang disebut dengan metode ceramah.

Seiring dengan perkembangan zaman, ilmu pengetahuan dan teknologi juga ikut berkembang. Teknologi dalam bidang pendidikan dapat digunakan sebagai sarana pendidikan, salah satunya yaitu media audio visual. Keberadaan teknologi dalam pelaksanaan pembelajaran khususnya sebagai media pembelajaran menjadikan kegiatan pembelajaran menjadi menarik dan bervariatif.

Penggunaan media audio visual dapat memberikan peserta didik dalam menyerap materi dengan baik dibandingkan dengan tidak menggunakan media pembelajaran. Sesuai

1 Permendikbud, Peraturan Menteri Pendidikan dan Kebudayaan Republik Indonesia No. 22 Tahun 2016 Tentang Standar Proses Pendidikan Dasar dan Menengah, 2016.

2 Andhita Dessy Wulansari, "Efektivitas Penerapan Metode Pembelajaran Student Teams Achievement Divisions dan Team Assisted Individualization Pada Materi Regresi Linier," Cendekia: Jurnal Kependidikan Dan Kemasyarakatan Vol 12 No (2014). 
dengan penjelasan Edgar Dale $^{3}$ terdapat kerucut pengalaman pembelajaran yang menyatakan bahwa seseorang dengan membaca dapat memberikan daya ingat sebesar $10 \%$, mendengarkan sebesar 20\%, melihat secara langsung sebesar 30\% seperti hanya melihat gambar, serta $50 \%$ jika peserta didik membaca dan mendengarkan misalnya menonton film, menonton demonstrasi dan sebagainya.

Media yang dipilih berkaitan dengan audio visual yaitu video pembelajaran stop motion. Video pembelajaran stop motion yang digunakan pada penelitian ini yaitu dengan bentuk tiga dimensi, video pembelajaran stopmotion ialah hasil gambar-gambaryang diabadikan menggunakan kamera dan digabungkan menjadi satu sehingga terlihat seakanakan menjadi bergerak dengan sendirinya, pada akhirnya menjadi sebuah video utuh. Menggunakan video pembelajaran stop motion ini berarti peserta didik dituntut untuk mendengar dan membaca, sehingga kegiatan tersebut lebih efektif dibandingkan dengan hanya membaca atau melihat saja. Dengan dipilihnya video stop motion diharapkan siswa fokus memerhatikan materi sehingga dapat memahaminya, karena video pembelajaran yang dibuat berupa film animasi yang memberikan kesan menarik dan tidak membosankan apabila disimak oleh peserta didiknya. Dengan dihadirkan video pembelajaran stop motion membuat peserta didik terbantu terkait memahami materi dengan sebaik mungkin.

Penelitian yang dilaksanakan pada Pratama dengan judul "Pengembangan Media Pembelajaran Video Stop Motion pada Pembelajaran Matematika", bahwa dengan dihadirkannya video stopmotion memberikan dampak positif terhadap guru atau peserta didik. Penggunaan video stop motion juga dapat memberikan pembelajaran yang efektif, siswa pun responsif terhadap pembelajaran, serta peserta didik dalam pembelajaran memiliki hasilpun mendapatkan peningkatan. Dari pada itu menggunakan video stop motion, saat belajar menjadi lebih efektif dan mendapatkan kategori "sangat baik", serta peserta didik merespon terkait video stop motion mendapatkan kategori "baik", dan pembelajaran peserta didik yang berprestasi mendapatkan kategori "baik".

Pelajaran yang dipilih pada video stop motion ini yaitu mata pelajaran matematika. Matematika menjadi salah satu rumpun ilmu yang dianggap sebagai pelajaran yang tidak mudah untuk dipahami, karena adanya proses berhitung dan memiliki sifat yang abstrak. Adapun data dari Fenan lampir et al. ${ }^{4}$ menyatakan bahwa Indonesia pada program TIMS (Trend In International Mathematic And Science Study) tahun 2011 mendapatkan peringkat 36 dari 40 negara yang mengikuti program TIMSS.

Oleh sebab itu peneliti menghadirkan video pembelajaran matematika pada materi perkalian. Dengan harapan dapat memudahkan peserta didik saat menghitung perkalian. Dengan demikian, dari paparan latar belakang, maka dilakukanlah penelitian dengan judul

\footnotetext{
3 Fatiya Rosyida danKhofifatu Rohmah Adi, "Pelatihan Pembuatan Media Pembelajaran dengan Program Autoplay untuk Guru-guru SMPN 2 Balen Kecamatan Balen Kabupaten Bojonegoro," Jurnal Praksis dan Dedikasi Sosial Vol 1 No 1 (2018).

4 Alberthus Fenanlampir, John Rafafy Batlolona, danImel dan Imelda, "The Struggle of Indonesian Students in the Context of TIMSS and PISA Has Not Ended," International Journal of Civil Engineering and Technology Vol 10 No (2019).
} 
pengembangan video pembelajaran stop motion dengan aplikasi wondershare filmora pada sekolah dasar terkait materi belajar matematika."

\section{B. METODE PENELITIAN}

Penelitiandilakukan dengan penggunaan metoderesearch and development (R\&D) untuk mengembangkan produk sebagai sumber belajar, sebagaimana pendapat yang disesuaikan dengan Sugiyono ${ }^{5}$ mengatakan bahwa penelitian pengembangan digunakan dalam menghasilkan produk. Adapun media yang dapat dikembangkan dalam penelitian yakni video pembelajaran stopmotion pada mata pelajaran matematika khususnya untuk materi perkalian. Kemudian setelah mengembangkan produk dilanjut dengan melakukan validasi, validasi terbagi menjadi dua yakni validasi pakar materi, dan pakar media. Kemudian diimplementaskan kepada siswa kelas III SDN Gorda 1 agar layaknya dapat diketahui terhadap media belajar video stop motion.

Prosedur pada penelitian dengan metode research and development ( $r \& d$ ) ataupun pengembangan ini digunakan dengan model penelitian ADDIE yakni singkatan dari Analysis, Design, Development, Implementation, dan Evaluation. Penggunaan model merupakan salah satu dalam pembelajaran agar dikembangkannya sebuah produk atau program yang efektif disebut juga dengan model ADDIE. Dipilihnya model ADDIE pada penelitian research and development ini berdasarkan dari alasan-alasan, yakni model ADDIE ini merupakan model yang sederhana, dengan mudah dipahami, serta praktis pada saat melakukan pengembangan media, sebab model ADDIE dapat dilaksanakan dengan cara bertahap sehingga dapat mencapai program yang menyeluruh, demikian tersebut dikemukakan oleh Pribadi. ${ }^{6}$

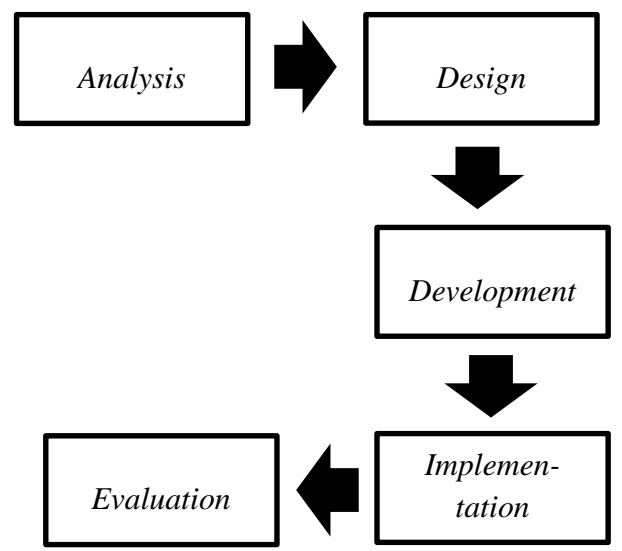

Diagram 1. Model ADDIE

\footnotetext{
5 Sugiyono, Metode Penelitian Kuali Kuanti dan R\&D (Bandung: Alfabeta, 2013), 297.

6 Pribadi Benny Agus, Desain dan Pengembangan Program Pelatihan Berbasis Kompetensi (Jakarta: Prenada Media Group, 2014), 22-23.
} 


\section{HASIL DAN PEMBAHASAN}

Penelitian pengembangan pada video pembelajaran stop motion dengan aplikasi wondershare filmora mata pelajaran matematika menggunakan metode penelitian R\&D.Tujuan pada penelitian yakni agar diketahui bagaimana langkah-langkah dalam dikembangkannya media belajar, selain itu agar mengetahui kelayakan dan respon pengguna terhadap videostop motion. Produk video pembelajaran stop motion ini dikembangkan dengan menggunakan tahapan model penelitian ADDIE dari Pribadi ${ }^{7}$, yakni.

1. Tahap Analisis (Analysis)

Terdapat dua tahap dalam kegiatan analisis, yakni analisis kinerja serta analisis kebutuhan. Analisis kinerjabergunaagar mengidentifikasiterjadinya sebuah masalah di sekolah, tentunya dikaitkan pada penggunaan media belajar, dengan cara mewawancarai wali kelas III SDN Gorda 1. Analisis kebutuhan yakni kegiatan yang dilakukan untuk mengetahui apa yang dibutuhkan sekolah atau siswa.

2. Design

Tahap kedua ini yaitu melakukan design yakni merancang. Pada tahap ini diawali dengan penyusunan materi yang disajikan pada media yang dikembangkan. Langkah selanjutnya yakni membuat story board. Storyboard dibuat dengan tujuan agar memudahkan dalam proses pembuatan produk yang akan dikembangkan atau dapat dikatakan sebagai acuan dalam pembuatan produk.

Tahap terakhir dari design yakni penyusunan kisi-kisi instrument agar dinilai kelayakan media dengan sedang dikembangkannya. Penilaian kelayakan media tersebut mencakup tiga angket yakni angket untuk validasi media, materi dan responden dari peserta didik.

3. Development

Pada tahapan ini yakni tahapan pengembangan produk. Design yang telah dirancang kemudian disajikan dalam bentuk media pembelajaran. Desain produk yang dikembangkan akan disajikan menjadi bentuk video pembelajaran. Video pembelajaran yang akan dikembangkan memuat gambar, video, audio, teks, dan animasi.

Tahap pengembangan ini, peneliti menyediakan berbagai bahan dan alat yang akan dipakai yakni berupa kain flanel, lem tembak, dakron, pensil, kardus, gunting, penggaris, lighting, tripod, kamera handphone, dan aplikasi wondershare filmora.

Setelah media pembelajaran dibuat, peneliti melakukan validasi kepada validator ahli media serta ahli materi. Kegiatan validasi dilakukan agar dinilai dari media pembelajaran yang akan dibuat. Ide-ide dari validator materi dan media dijadikan sebagai 
premis atau acuan untuk memperbarui media agar menjadi media pembelajaran yang layak.

Berikut ini merupakan hasil kelayakan media dari tim validasi media dan materi produk video pembelajaran stop motion:

1. Validasi Ahli Media

Validasi ahli media dilaksanakan melalui dua ahli media, guna untuk memperoleh video pembelajaran stop motion yang layak sehingga dapat diuji cobakan kepada peserta didik kelas III SDN Gorda 1.

Tabel 1. Penilaian Validasi Ahli Media

\begin{tabular}{|c|c|c|c|c|c|}
\hline \multirow{2}{*}{ Validator } & \multicolumn{3}{|c|}{ Aspek } & \multirow{2}{*}{$/ \mathrm{SM}$} & NP\% \\
\cline { 2 - 4 } & $\mathrm{P}$ & $\mathrm{D}$ & $\mathrm{A}$ & & \\
\hline I & 20 & 42 & 19 & 95 & $89,5 \%$ \\
\hline II & 23 & 47 & 20 & 95 & $94,7 \%$ \\
\hline Rata-rata & \multicolumn{3}{|c}{$91,3 \%$} \\
\hline
\end{tabular}

Berdasarkan tabel di atas adalah hasil validasi media dari tim ahli media I memperoleh skor $89,5 \%$ dan ahli media II memperoleh skor 94,7\%, sehingga rerata pada keduanya skor yakni 92,1\% dengan kategori sangat layak.

2. Validasi Ahli Materi

Validasi ahli materi dilaksanakan melalui dua ahli materi. Validasi materi mencakup 3 aspek, diantaranya aspek kurikulum, materi, dan pengguna. Berikut ini merupakan hasilnya dari validasi materi.

Tabel 2. Penilaian Validasi Ahli Materi

\begin{tabular}{|c|c|c|c|c|c|}
\hline \multirow{2}{*}{ Validator } & \multicolumn{3}{|c|}{ Aspek } & \multirow{2}{*}{ /SM } & \multirow{2}{*}{ NP\% } \\
\cline { 2 - 5 } & $\mathrm{K}$ & $\mathrm{M}$ & $\mathrm{P}$ & 75 & $89,33 \%$ \\
\hline I & 14 & 36 & 17 & 75 & $81,3 \%$ \\
\hline II & 13 & 34 & 14 & $85,3 \%$ \\
\hline
\end{tabular}

Berdasarkan tabel tersebut adalah hasil validasi materi dari tim ahli materi I memperolehskor 89,33\% dan ahli materi II memperoleh skor 81,3\%, sehingga dari ratarata kedua skor tersebut $85,3 \%$ dengan kategori sangat layak.

\section{Implementation}

Implementasi dilakukan untuk mengetahui respon pengguna terhadap produk, dengan jumlah peserta didik kelas III SDN Gorda 1 sebanyak 21 orang. Berikut ini hasil penilaian respon pengguna media pembelajaran.

\section{Tabel 3. Penilaian Hasil Responden Peserta Didik}

\begin{tabular}{|c|c|c|c|}
\hline Aspek & Jumlah skor & Skor maksimal & Persentase \\
\hline Tampilan, penggunaan media, dan manfaat & 246 & 252 & $97,6 \%$ \\
\hline
\end{tabular}


Berdasarkan data padatabel di atas menunjukkan hasil tanggapan peserta didik pada tahap skala besar mendapatkan skor tertinggi sebesar $100 \%$ dan terendah $83,3 \%$, sehingga mendapatkan rata-rata skornya yakni 97,6\% merupakan kriteria "Sangat Baik". Jadi media belajar dengan peneliti kembangkan dapat diujicobakan saat aktifitas belajar untuk peserta didik di kelas III SDN Gorda 1.

\section{Evaluate}

Tahap evaluasi ini berisikan penilaian terhadap produk yang telah peneliti kembangkan.

Penelitian ini menggunakan evaluasi formatif karena pada penelitian ini bukan untuk mengetahui efektivitas pada produk yang dikembangkan, melainkan mengetahui layak atau tidaknya video pembelajaran stopmotion. Kegiatan evaluasi ini dilakukan pada saat validasi kepada validator ahli media dan materi, sehingga mendapatkan saran atau komentar untuk meningkatkan produk yang sedang dikembangkan dan menjadi media yang memiliki kategori layak untuk digunakan.

Berdasarkan uraian pembahasan tersebut menyimpulkan pada video pembelajaran stop motion materi perkalian pada mata pelajaran matematika layak digunakan di lapangan karena sesuai dengan hasil validasi media dan materi oleh validator serta hasil respon peserta didik yang telah memenuhi kategori keberhasilan.

\section{PENUTUP}

\section{Simpulan}

1. Media pembelajaran yang dikembangkan yakni video pembelajaran stop motion yang diimplementasikan kepada peserta didik kelas III SDN Gorda 1, dengan responden berjumlah 21 siswa kelas III. Penelitian ini dilakukan dengan menggunakan model ADDIE.

2. Video pembelajaran stop motion dengan aplikasi wondershare filmora pada mata pelajaran matematika di sekolah dasar sudah mendapatkan kategori sangat layak untuk dipergunakan. Hal ini berdasarkan penilaian tim validasi ahli media, materi dan respon dari peserta didik. Adapun penilaian melalui validator ahli media yakni mendapatkan persentase 92,1\% sehingga memiliki kriteria sangat layak. Penilaian melalui validator ahli materi yakni 85,3\% dalam kategori sangat layak.

3. Video pembelajaran stop motion mendapatkan penilaian dari respon peserta didik yakni $97,6 \%$ kriteria sangat baik.

Pemaparan hasil keseluruhan dari penilai itu dengan ditunjukan pada video pembelajaran stop motion dengan telah dikembangkannya sangat layak dalam dipergunakan untuk media belajar. 


\section{Saran}

Berdasar hasil penelitian dan pengembangan video pembelajaran stop motion dengan aplikasi wondershare filmora pada mata pelajaran matematika menunjukkan bahwa media tersebut berpengaruh terhadap pembelajaran yakni menghitung hasil perkalian, karena dari dilihatnya hasil penilaian responden peserta didik dengan menunjukkan perolehan skor persentase lebih besar. Oleh sebab itu, pemberian sebagian saran dengan peneliti dapat dijadikan sebagai rekomendasi, yakni sebagai berikut :

1. bagi peserta didik, sebaiknya video pembelajaran stop motion ini digunakan berulangulang kali sehingga peserta didik tidak mudah lupa untuk menghitung hasil perkalian.

2. bagi pendidik, hendaknya dapat lebih kreatif mengembangkan media berbasis teknologi dengan karakteristik peserta didik yang disesuaikan pada sekolah dasar.

3. kegiatan pembelajaran sebaiknya sesering mungkin menggunakan media, dankemudahan pada peserta didik dalam pemahaman dadari isi materi belajar.

\section{E. DAFTAR PUSTAKA}

Agus, Pribadi Benny. Desain dan Pengembangan Program Pelatihan Berbasis Kompetensi. Jakarta: Prenada Media Group, 2014.

Fenanlampir, Alberthus, John Rafafy Batlolona, dan Imelda Imelda. "The Struggle of Indonesian Students in the Context of TIMSS and PISA Has Not Ended." International Journal of Civil Engineering and Technology Vol 10 No (2019).

Permendikbud. Peraturan Menteri Pendidikan dan Kebudayaan Republik Indonesia No. 22 Tahun 2016 Tentang Standar Proses Pendidikan Dasar Dan Menengah, 2016.

Rosyida, Fatiya, and Khofifatu Rohmah Adi. "Pelatihan Pembuatan Media Pembelajaran dengan Program Autoplay Untuk Guru-guru SMPN 2 Balen Kecamatan Balen Kabupaten Bojonegoro." Jurnal Praksis Dan Dedikasi Sosial Vol 1 No 1 (2018).

Sugiyono. Metode Penelitian Kuali Kuanti Dan R\&D. Bandung: Alfabeta, 2013.

Wulansari, Andhita Dessy. "Efektivitas Penerapan Metode Pembelajaran Student Teams Achievement Divisions dan Team Assisted Individualization Pada Materi Regresi Linier." Cendekia: Jurnal Kependidikan dan Kemasyarakatan Vol 12 No (2014). 